\title{
Aventura e Rotina e Baltasar Lopes ou a adiada identificação africana de Cabo Verde
}

\author{
Aventura e Rotina and Baltasar Lopes or the delayed \\ African identification of Cape Verde
}

Daniel António Pereira*

RESUMO: REACENDE UM VELHO DEBATE, AINDA BEM VIVO EM CABO VERDE, ACERCA DA IDENTIFICAÇÃO AFRICANA DOS CABO-VERDIANOS, DESPOLETADA COM AS IDEIAS DE GILBERTO FREYRE SOBRE O ARQUIPÉLAGO, REBATIDAS, COM VEEMÊNCIA POR BALTASAR LOPES DA SILVA. O AUTOR TENTA DESMISTIFICAR TANTO AS ASSERÇÕES DE FREYRE, QUANTO A DEFESA DO AUTOR DE CHIQUINHO, PARTINDO DAS OBSERVAÇÕES E ANÁLISES DESTES DOIS ÍCONES DA CULTURA DO BRASIL E DE CABO VERDE, NÃO ISENTOS DE CRÍTICA PELA SUA POSTURA INTELECTUAL.

ABSTRACT: THE REKINDLING OF AN OLD DEBATE, WHICH IS STILL VERY MUCH ALIVE IN CAPE VERDE, CONCERNING THE AFRICAN IDENTIFICATION OF THE CAPE VERDEANS, IS SPARKED WITH GILBERTO FREYRE'S IDEAS ABOUT THE ARCHIPELAGO, AND DEBATED STRONGLY BY BALTASAR LOPES DA SILVA. THE AUTHER ATTEMPTS TO DEMYSTIFY THE CLAIMS OF FREYRE, IN DEFENSE FOR THE AUTHOR OF CHIQUINHO, STARTING WITH THE OBSERVATIONS AND ANALYSIS OF THESE TWO ICONS OF THE CULTURE OF BRAZIL AND CAPE VERDE, THAT ARE NOT IMMUNE FROM CRITICISM FOR THEIR INTELLECTUAL STANCE.

PALAVRAS-CHAVE: IDENTIDADE E IDENTIFICAÇÃO DO CABO-VERDIANO; DEBATE NECESSÁRIO E DESAPAIXONADO; BALTASAR LOPES; GILBERTO FREYRE.

KEYWORDS: CAPE VERDEAN IDENTITY; NEEDED DEBATE; BALTASAR LOPES; GILBERTO FREYRE.

\footnotetext{
* Embaixador da República de Cabo Verde no Brasil, Brasília, Distrito Federal, Brasil. Historiador, tendo publicado, entre outros títulos, A importância histórica da Cidade Velha (2004), Estudos da história de Cabo Verde (2005), Das relações históricas Cabo Verde/ Brasil (2011), Cidade da Praia de Santiago: no compasso do tempo (2012). E-mail: embaixador@embcv.org.br.
} 
abe-se que, a convite do Governo português, o sociólogo brasileiro Gilberto Freyre empreendeu, de agosto de 1951 a fevereiro de 1952, uma viagem pelos então territórios sob dominação colonial portuguesa. Como resultado dessa visita, que durou seis meses, foi publicado, em 1953, primeiro no Rio de Janeiro e depois em Lisboa, o livro Aventura e rotina, cujo subtítulo era sugestões de uma viagem à procura das constantes portuguesas de caráter e ação.

Muitas vezes ouvi falar deste livro, depois lido integralmente, que tinha provocado acesa polêmica em Cabo Verde, com reações muito contundentes, principalmente por parte de Baltasar Lopes da Silva, nada satisfeito com as observações de Gilberto Freyre acerca de Cabo Verde, aquando da sua passagem por algumas das nossas ilhas, em outubro de 1951, no quadro da referida viagem, que causou, igualmente, reações políticas intempestivas, tanto em Portugal como no Brasil, pela admiração que o Presidente do Conselho de Portugal, António de Oliveira Salazar, suscitava a Gilberto Freyre ${ }^{11}$, a ponto deste o elogiar e mesmo justificar o seu regime político, postura paradoxal, porém, de quem fora, por outro lado, "um tenaz opositor do fascismo e do Estado Novo brasileiro" (SILVA, Prefácio a FREYRE, 1999, p. 13).

Não se julgue, no entanto, que o brilhante autor de Casa Grande \& Senzala não criticou o regime na sua obra, face às observações que fez ao longo de toda a sua digressão pelas antigas colônias portuguesas. Só que, como avalia Alberto da Costa e Silva,

Gilberto Freyre era um gentleman, um homem muitíssimo bem-educado, incapaz de ofender ou magoar o hospedeiro. $\mathrm{Na}$ maioria das vezes que se vê constrangido a criticar, envolve as farpas em algodão para que só arranhem e, se possível, de leve. Ao leitor sagaz não escaparão, porém, as sentenças que vai passando, por exemplo, contra a falta de liberdade de expressão [...] (Ibidem, p. 17-20).

Para mais, Freyre esteve sempre muito condicionado na sua digressão, sobretudo na África. Por isso mesmo, escreve Costa e Silva:

1. Em tradução livre, "já me tornei branco", no sentido em que um determinado indivíduo ganhou suficiente importância econômica para ascender à condição social de branco, tendo adquirido posses. Portanto, "branco" no sentido social e econômico do termo, não com caráter étnico. 
Foi pena que na África não o deixassem demorar o olhar sobre o que mais podia interessá-lo. A impressão que nos fica é a de que dele não se afastaram um só momento as autoridades coloniais... E não andou sozinho por parte alguma. Parecia haver a intenção de que não visse a África e os africanos, mas tão-somente o que se fizera português na África (Ibidem, p. 18).

Como se verifica, o livro de Gilberto Freyre foi escrito poucos anos depois do fim da II Guerra Mundial (1951/52), num ambiente de início das independências das antigas colônias, como era o caso, por exemplo, da Índia. $\mathrm{Na}$ África ainda faltavam cerca de cinco anos para a independência do Gana.

Ou seja, a recusa ao direito de autodeterminação, que caracterizou a política ultramarina portuguesa, ainda contaria vários anos antes de começar a tornar-se um anacronismo.

Dissemos anteriormente que as reações de Baltasar Lopes acerca das impressões deixadas por Gilberto Freyre no seu livro Aventura e rotina, na parte respeitante a Cabo Verde, não foram as melhores. Bem antes pelo contrário.

Assim, na sequência da publicação da obra em Portugal, em 1953, chegados os ecos da mesma a Cabo Verde, numa resposta lida aos microfones da Rádio Barlavento, no Mindelo², Baltasar Lopes começa por afirmar que Gilberto Freyre não conhecia efetivamente Cabo Verde, já que o tempo passado em algumas das nossas ilhas era demasiado escasso para permitir qualquer análise de fundo perante observações que só poderiam ser ligeiras, feitas por uma pessoa que apenas estava de passagem.

À primeira vista e neste particular, devemos dar razão a Baltasar Lopes. Aliás, outros autores, como Manuel Ferreira, também se insurgiram, quase nos mesmos termos, às asserções feitas por Gilberto Freyre a propósito da sua curta estadia em Cabo Verde. Na realidade, pela leitura do livro se pode verificar que Gilberto Freyre deve ter estado no máximo duas semanas em Cabo Verde, senão menos ainda, porque, como se pode facilmente constatar, deve ter chegado à antiga Guiné, dita então portuguesa, no começo de outubro. Começou a sua estadia pela ilha de Santiago, onde pode ter chegado,

2. Esta resposta, em vários módulos separados, foi depois editada, em forma de opúsculo, com o título "Cabo Verde visto por Gilberto Freyre", Boletim de Propaganda e Informação, Praia, Imprensa Nacional, 1956. Este debate tem marcado gerações desde essa época. Continua a causar muito furor entre os intelectuais cabo-verdianos, e é quase referido, em sua defesa ou rejeição, mais com paixão do que com a razão. 
provavelmente durante a terceira semana de outubro de 1951, tendo, depois, visitado, sucessivamente, as ilhas de São Vicente e do Sal, donde partiu, de avião, para Lisboa, mesmo nos finais de outubro, porque novembro o encontra já na cidade tagitana.

Mas afinal, o que verdadeiramente escreveu Gilberto Freyre sobre Cabo Verde no seu livro Aventura e rotina?

Vejamos, resumidamente:

[...] Mas no que o primeiro contato com Cabo Verde me faz principalmente pensar é na miscigenação que aqui foi ensaiada de modo intenso pelo português, com judeus e, notadamente, com negros, antes de ser desenvolvida na América tropical, sobre o lastro ameríndio. O primeiro caldeirão de ensaio dessa aventura étnica foi esta ilha de São Tiago, hoje tão negróide: sinal de que, ao contrário do que vem sucedendo, cada vez mais, no Brasil, o grosso da população vem mantendo o elemento de origem africana.

Tinham-me dito que eu viria encontrar em Cabo Verde uma paisagem e uma população semelhante às de certas áreas do nordeste do Brasil; e há com efeito traços de parentesco entre certas paisagens do Brasil e as de um Cabo Verde às vezes tropicalmente rico de verdes de mata que contrastam com os azuis do mar. Mas o parentesco entre as populações e as culturas lusotropicais que se vêm desenvolvendo naquelas áreas brasileiras e as que parecem ter já estabilizado em São Tiago, e talvez noutras ilhas de Cabo Verde, este parentesco me parece vago; e não tão acentuado que em Cabo Verde se tenha sempre a impressão de estar entre parentes próximos, ao mesmo tempo, dos portugueses e dos brasileiros.

Confesso que minha mais forte impressão em São Tiago é a de estar numa espécie de Martinica que em vez de afro-francesa fosse afro-portuguesa, ou numa Trinidad que em vez de afro-inglesa fosse afro-lusitana: ilhas em que as populações fossem predominantemente africanas na cor, no aspecto e nos costumes, com salpicos, apenas, de influência européia, sobre essa predominância étnica e social. A presença dominante do europeu apenas se revela no que é oficial: edifícios, ritos de administração, o trajo, o andar, a fala dos burocratas e dos negociantes mais importantes. Não que estes indivíduos sejam sempre europeus no sangue; mas são invariavelmente "europeus" ou "americanos" nos seus modos de ser e no português que falam. 
Porque uma das semelhanças de São Tiago com as pequenas antilhas inglesas e principalmente francesas vem do fato de que aqui, como em quase o arquipélago inteiro, se fala um dialeto que nenhum português ou brasileiro é capaz de compreender senão depois de iniciado nos seus segredos. É a primeira impressão de exótico que dá Cabo Verde a qualquer brasileiro. [...] É de certo modo esta a impressão que sinto em face da gente do povo de São Tiago: a impressão de uma população sociológica e até etnicamente aparentada com a portuguesa ou a brasileira, mas demasiadamente dominada pela herança da cultura e da raça africanas para que seu parentesco com portugueses e brasileiros seja maior que o exotismo de sua aparência e de seus costumes. Costumes, muitos deles, ainda solidamente africanos. Outros de tal modo africanóides que retêm sua potência africana sob o verniz europeu [...] (FREYRE, 1999, p. 266-267).

Já falaremos mais adiante dessas primeiras impressões de Giberto Freyre sobre a ilha de Santiago, tentando dissecar as suas observações, segundo Baltasar Lopes, demasiado apressadas, deixando-se o sociólogo brasileiro levarse apenas pelas aparências que o momento lhe deixou entrever levemente, difícil de perceber num cientista social da sua dimensão e envergadura.

De fato, se o melhor da atenção de Gilberto Freyre se voltava para as mestiçagens entre grupos humanos e as trocas, somas e mesclas de culturas que se processavam nas regiões visitadas, é no mínimo estranho que ele não se tenha entusiasmado minimamente com o arquipélago cabo-verdiano. $\mathrm{Na}$ asserção de Alberto da Costa e Silva, tal só aconteceu porque, provavelmente, "dele só lhe deixaram ver tão pouco que não chegou a compreendê-lo" (SILVA, in FREYRE, 1999, p. 22).

$\mathrm{E}$, no entanto, Freyre contatou eminentes figuras durante a sua digressão à Guiné e a Cabo Verde, excelentes interlocutores e informantes de grande peso, que poderiam ajudar na sua compreensão das terras que visitava. Referimo-nos a Avelino Teixeira da Mota, António Carreira, de quem elogia a proficiência e os conhecimentos; José Lopes, Manuel Lopes, Jorge Barbosa, Júlio Monteiro, para só citar alguns. Baltasar Lopes, nessa ocasião, estava ausente do Mindelo em visita ao Brasil. Coincidências!

Reparemos agora nas impressões que nos deixou Gilberto Freyre sobre a ilha do Porto Grande: 
Minha primeira impressão de São Vicente é a de uma ilha de gente mais alegre que a de São Tiago: com alguma coisa de baiano e até de carioca. De malandro, portanto.

Mas o grau de mestiçagem me parece, à primeira vista, o mesmo nas duas ilhas crioulas: a mesma predominância do africano sobre o europeu que nas pequenas Antilhas.

[...] Nota-se em São Vicente maior número de mulatos alourados do que em São Tiago. Nas origens de muitos cabo-verdianos há, além de portugueses, franceses, espanhóis e holandeses: europeus que frequentavam essas ilhas antes de desiludirem de encontrar nelas riqueza fácil. São Vicente continuou até quase os nossos dias frequentada por ingleses. Ingleses de companhias de carvão e ingleses do Cabo Submarino. E desses ingleses é evidente que alguns, seguindo aliás o exemplo dos portugueses, concorreram para arianizar a população predominantemente africana da ilha: são numerosos os mulatos alourados que se vêem em São Vicente. Alguns de pele tão clara e olhos tão azuis que, julgados pelo observador menos perito em surpreender sobrevivências africanas em mestiços quase brancos, podem passar por brancos. Até mesmo por ingleses um tanto desanglicizados pelos trópicos (FREYRE, 1999, p. 270-271).

É inquestionável a influência de culturas africanas em Cabo Verde, muito particularmente nas ilhas de povoamento antigo, como são as de Santiago e do Fogo, onde aliás se construiu a matriz, que deu lugar à chamada cabo-verdianidade, depois transplantada para as restantes ilhas do arquipélago, que, por sua vez, foi sofrendo novos acrescentos. Essa matriz resultou de um processo evolutivo, tratando-se, portanto, de uma construção historicamente datada.

Ao contrário do que Gilberto Freyre deixa perceber nas suas observações e juízos, o processo de mestiçagem que se verificou em Cabo Verde foi bem mais profundo do que mediamente se poderia imaginar. Se apenas leu Cristiano José de Sena Barcelos, como nos fica a impressão, considerando a data da sua passagem por Cabo Verde (1951), seria difícil, para ele, entender minimamente a história da mestiçagem nas ilhas cabo-verdianas.

Face às impressões que nos transmitiu, provavelmente ficaria espantado se soubesse, por exemplo, da existência de dois escritores quinhentistas naturais de Cabo Verde (ilha de Santiago), mestiços de tez escura, um dos quais, André Álvares de Almada, foi agraciado com a prebenda da Ordem de Cristo, 
apesar do evidente da sua coloração cutânea, por causa dos relevantes serviços prestados à Coroa portuguesa. Ele foi o autor do Tratado breve dos Rios de Guiné, escrito em 1594. O outro foi André D’Ornelas ou Donelha, que escreveu a Descrição da Costa de Guiné, datado de 7 de novembro 1625.

O espanto persistiria se conhecesse que, em 1546, uma petição de homens baços e pretos de Santiago solicitava lhes fosse reconhecida qualidade bastante para poderem ascender aos "ofícios do Concelho", como anteriormente se fizera com relação aos da ilha de São Tomé, o que lhes foi concedido.

Seria igualmente perturbante se conhecesse que escravos ladinos, oriundos de Cabo Verde, eram tipificados por Sasseti, na Lisboa quinhentista, de que $10 \%$ da população era escrava, como "sabendo fazer tudo, até tocar música", mas "soberbos e altivos", afinal alguns dos traços psicológicos característicos daquele que se veio a perfilar como o homem cabo-verdiano.

Perturbaria também, certamente, o fato de saber que, já no primeiro quartel do século XVII, eram os "brancos de terra" que dominavam política e economicamente as ilhas principais (Santiago e Fogo); que eram os mestiços a ocupar os cargos camarários; que eram eles também a constituir as elites dominantes no Cabo Verde de então. O testemunho do Padre Jesuíta Sebastião Gomes, em 1617, é elucidativo a este respeito, quando afirma, a propósito da fundação do Colégio Jesuítico na Ribeira Grande³, o seguinte:

Quando nos pediram havia muita gente de Portugal, e na Câmara raramente entrava crioulo, e que não fosse de Portugal, e por isso nos desejavam na terra [...] Estes homens quase todos são mortos, e chegou a terra a tais termos, que quantos há hoje na Câmara são crioulos (BRÁSIO, Vol. IV, Doc. 149, p. 613).

Seria para lá de perturbador encontrar um Governador de Cabo Verde, nado e criado na ilha de Santiago, como foi Pedro Semedo Cardoso, entre 1650/51. Esse deve ser caso único nas sociedades esclavagistas da época moderna, implantadas nas ilhas do Atlântico e no Novo Mundo.

Do mesmo modo, a existência de padres "negros como azeviche" que o Padre António Vieira encontrou na ilha de Santiago e que, como escreveu,

3. Com o propósito de criar um Colégio na Cidade da Ribeira Grande, os Jesuítas chegaram a Cabo Verde em julho de 1604. 
"só nesse particular" se diferenciavam dos de Portugal, "porque tão doutos, tão morigerados e tão bons músicos, que fazem inveja aos melhores das Catedrais de Portugal". E os exemplos poderiam multiplicar-se por aí fora.

O escritor Manuel Ferreira, no seu trabalho $A$ aventura crioula on Cabo Verdeuma sintese cultural e étnica, defendia, com propriedade, que esses fatos faziam sobressair "não só o quão cedo o mestiço de Cabo Verde soube (ou pôde) tornar-se um homem a quem não molestavam complexos de inferioridade, como também de um clima social onde o branco aceitou o mando do mestiço” (FERREIRA, 1973, p. 23).

Gabriel Mariano vai ainda mais longe nessa defesa, ao afirmar que, diferentemente do que sucedeu nos outros territórios colonizados por portugueses, em Cabo Verde "foram os negros e os mulatos os responsáveis diretos na estruturação da sociedade" (1959), o que parece não ter sido o caso no Brasil, por exemplo.

Aliás, as razões que temos vindo a expender explicam, de algum modo, a quase ausência de racismo no meio social cabo-verdiano. Aqui, o econômico será, desde cedo, fator de promoção social, de "brancalização".

Assim se entende, por exemplo, que negros, pelo simples fato de usarem sapatos, fossem tratados por brancos, como tantas vezes aparece referido na documentação de arquivo do século XVIII. Não será, por isso, a coloração cutânea que definirá o estatuto social, mas a situação econômica de cada um, com todas as contradições que a ideia pode enformar. Como observará Félix Monteiro, estamos perante uma sociedade onde o branco não tem cor e o rico não tem dinheiro. Esta é uma criação, diria, genuinamente cabo-verdiana, que se sublima, magistralmente, numa frase dramática da língua cabo-verdiana, pela sua dimensão e conotação, alienante embora, e que tantas vezes escutamos: "djan branku dja".

Resumindo: no início da colonização, dada a escassez de brancos e a forma ampla como se planeou o povoamento, recorreu-se a africanos da Costa de Guiné para suprir a falta de mão de obra e, do contato das duas populações, desencadeou-se a mestiçagem. De tal modo que, já em 1620, este processo

4. Em tradução livre, "já me tornei branco", no sentido em que um determinado indivíduo ganhou suficiente importância econômica para ascender à condição social de branco, tendo adquirido posses. Portanto, "branco" no sentido social e econômico do termo, não com caráter étnico. 
tinha tamanha intensidade, que se ordenava o envio, para Cabo Verde, de mulheres brancas que se degredavam antes para o Brasil, para que se extinguisse o mais rapidamente possível a raça dos mulatos (PEREIRA, 2009, p. 126).

Logo, do contato íntimo entre escravos e colonos brancos resultou uma troca de culturas, que se fundiram com uma certa harmonia em Cabo Verde. Esta fusão, desde o início, deu uma feição especial à sociedade cabo-verdiana, com contribuições significativas seja da cultura portuguesa, seja da africana.

Estão aqui testados, de forma soberana, alguns dos ingredientes fundamentais do que se convencionou chamar de lusotropicalismo, a teoria que, durante a viagem de Gilberto Freyre, deu lugar ao seu livro, Aventura e rotina, que passou a ter esse nome, pretendendo com ele explicar certos e determinados aspectos ligados à ocupação portuguesa nos espaços tropicais, o modo português de interpenetração de culturas que acompanhavam a miscigenação de raças e povos.

Simplesmente, alguns dos elementos da teoria de Gilberto Freyre não se colavam à realidade que encontrou em Cabo Verde. Desde logo a existência de uma língua própria, a cabo-verdiana, que ele abominou, sem qualquer espécie de reserva: "do mesmo modo que me repugna o dialecto cabo-verdiano, agrada-me ouvir a gente cabo-verdiana falar o português à sua maneira, que é a maneira tropical, brasileira, não sei se diga sempre com 'açúcar"' (FREYRE, 1999, p. 274).

Isso significa que estamos perante um bilinguismo que não surgiu no Brasil, mesmo em presença de povos autóctones, que falavam diversas línguas. O nascimento de uma terceira língua em Cabo Verde contraria a dispersão geográfica das ilhas, uma língua franca, para contrariar a babel de línguas iniciais, trazidas por sucessivos lotes de escravos da Costa Ocidental africana das mais variadas etnias, num total de cerca de vinte e seis que estiveram na base da formação social e cultural cabo-verdiana. Por isso, o cabo-verdiano se consubstanciou numa língua síntese das línguas em presença nas nossas ilhas, desde o início. De tal forma que, já nos finais do século XVII, o crioulo era considerado língua de ensino da própria catequese, no processo de ladinização dos escravos, que já vinha de trás.

Donde, também, o fato de, em Cabo Verde, paradoxalmente, a Nação ter antecedido o Estado, ainda que a consciência dessa realidade tenha surgido bem mais tarde. No Brasil, pelo contrário, a Nação foi uma construção do próprio Estado. 
Em menos de duas semanas de estadia em três das nossas ilhas seria difícil ter a percepção de todos estes fatos, por maior que fosse a capacidade de observação e a sagacidade de Gilberto Freyre, em quem se reconhece, não obstante, uma grande envergadura intelectual e um cientista social de enorme traquejo, não só no Brasil, mas em nível internacional. De igual modo, essa passagem, quase de raspão, pela ilha de Santiago, onde Gilberto Freyre parece ter estado apenas na cidade da Praia e na antiga cidade da Ribeira Grande, hoje cidade de Santiago de Cabo Verde, a primeira capital do nosso arquipélago, não permitiu ao sociólogo brasileiro vislumbrar, por exemplo, nenhum vestígio de "uma arte popular que seja própria do cabo-verdiano e marque, em sua cultura, uma sobrevivência africana cultivada com algum carinho..." (FREYRE, 1999, p. 276).

Para este autor, tratava-se de uma "incaracterização cultural" ou uma

instabilidade cultural de que são indícios: por um lado, o uso generalizado, pelos ilhéus, de um dialecto; e, por outro lado, a ausência entre esses mesmos ilhéus, de artes populares em que se exprimisse uma saudável interpenetração das culturas que neles se cruzam, sem se terem harmonizado, até hoje - a não ser, talvez, na música - numa terceira cultura, característicamente cabo-verdiana (FREYRE, 1999, p. 276-277).

Foram todos estes elementos culturais conjugados que levaram Baltasar Lopes a afirmar e a defender, com veemência, que os cabo-verdianos não eram nem europeus, nem africanos, mas cabo-verdianos (LOPES, 1956).

Compreende-se, perfeitamente, o contexto em que essa asserção foi proferida. Mas ela teve um enorme impacto na sociedade e na mentalidade dos cabo-verdianos até hoje. Na verdade, esta célebre frase, para o bem e para o mal, tem sido comentada de vários pontos de vista. É, sobretudo, campo para muita ambiguidade, política, cultural e sociológica, cuja elasticidade tem, naturalmente, os seus limites, dificultando, e de que maneira, a nossa identificação enquanto africanos de parte inteira.

Este é um debate antigo, que Baltasar Lopes suscitou, em novos moldes, quando, antes, os Nativistas defendiam Cabo Verde como ilhas adjacentes de Portugal e, nessa senda, afirmavam a cultura cabo-verdiana como um caso de regionalismo português, enquanto os nacionalistas, que emergiram a partir 
dos meados da década de cinquenta do século passado, entendiam-na, antes, como um caso de regionalismo africano.

Esse debate tem outros condimentos, já pressentidos por Gilberto Freyre, em 1951, e que ainda são elementos do nosso cotidiano hodierno, quando muitos cabo-verdianos buscam ou pretendem a sua identificação africana, contrariada, sobretudo, por certos intelectuais e políticos, logo por uma determinada elite.

Diga-se, para se evitar qualquer confusão epistemológica, que identidade e identificação se podem justapor, mas não se devem confundir.

Efetivamente e de maneira muito simplificada, enquanto identidade tem a ver com um conjunto de caracteres próprios e exclusivos que caracterizam uma certa comunidade, do ponto vista étnico e/ou cultural, a identificação tem a ver mais com confluências, semelhanças, pertenças e proximidades culturais, físicas ou geográficas com os outros.

É evidente que Gilberto Freyre quis, de certo modo, fazer sobressair a componente africana da nossa cultura. Certo é, porém, que, infelizmente, Freyre não conseguiu descortinar que estava, quiçá, perante uma das sínteses culturais das mais harmoniosas que, alguma vez, conseguiu-se construir no seio das sociedades escravistas do período moderno, que se implantaram no Atlântico, em particular nas ilhas e no Novo Mundo.

As suas observações, consideradas no mínimo apressadas, fizeram-no ajuizar precisamente o inverso. É que havia muito que o cruzamento de culturas (europeia e africanas) em Cabo Verde tinha produzido sincretismo religioso, no culto dos seus mortos, na Tabanca, no Kolá S. Jon, nos tambores que acompanham, praticamente, todas as Festas Juninas, como as anteriormente enunciadas, nas Cavalhadas do Fogo e, igualmente, a arte popular que ele não viu, porque, provavelmente, não terá ido além da Praia.

Quero crer que estas circunstâncias, que fizeram com que Baltasar Lopes interviesse da forma como aconteceu, têm muito a ver com a necessidade de querer demonstrar a Gilberto Freyre e não só, que, afinal, existia uma cultura identitária em Cabo Verde, que tinha nascido do processo de cruzamento de culturas em presença nas nossas ilhas, coisa que esse autor brasileiro não conseguiu discernir, pelas razões antes aduzidas.

Mas, dizia antes, Freyre tinha pressentido outros condimentos do debate sobre as origens africanas da nossa cultura que, quase sessenta anos depois, 
revelam-se de uma atualidade impressionante, causando, ainda, esse debate, muito "frison", mas que tem mais a ver com estados de alma do que com a razão.

Escrevia Gilberto Freyre a este propósito, no quadro das observações que vimos apresentando:

Das origens africanas o cabo-verdiano já perdeu, talvez, o melhor; e quanto às sobrevivências africanas em sua cultura, a atitude do maior número tende a ser uma atitude de pudor que faz de muito cabo-verdiano mestiço um envergonhado daquela sua origem [...], uma gente que, procurando ser europeia, repudia suas origens africanas e encontra-se, em grande número, em estado ou situação precária de instabilidade cultural e não apenas econômica (FREYRE, 1999, p. 276-277).

Com estes novos elementos, voltemos, então, à célebre frase da criação de Baltasar Lopes da Silva, segundo a qual os cabo-verdianos não são nem europeus, nem africanos, mas cabo-verdianos.

Já tivemos oportunidade de sublinhar, anteriormente, que compreendíamos, perfeitamente, o contexto e as condições em que essa afirmação foi proferida, querendo com ela deixar claro que, ao contrário das conclusões de Gilberto Freyre acerca do processo de miscigenação em Cabo Verde, esta foi um fato incontornável, aconteceu bem cedo e atingiu uma dimensão, profundidade e densidades muito elevadas, consideradas as condições históricas em que ela se processou.

Sendo certo que essa afirmação não pode ser transplantada, mecanicamente, para a realidade atual, a verdade é que, sempre que se fala da necessidade da nossa identificação enquanto africanos de parte inteira, essa frase é acenada para obstar a tal. Tendo sido produzida por quem era e ainda é considerado "O monstro sagrado" da literatura e cultura cabo-verdianas, importa, no entanto, a sua desmontagem, diria mesmo a sua desminagem.

Desde logo, essa frase é, em si, redundante e tautológica. Trata-se, ao cabo e ao resto, de uma repetição inútil de uma mesma ideia em termos diferentes. O cabo-verdiano é cabo-verdiano, como o senegalês é senegalês, o sueco, sueco e o português, português. Nem por isso deixam de ser, simultaneamente, também africanos ou europeus. 
Depois, ela encerra no seu bojo uma tese isolacionista, agregando maiores dificuldades ao isolamento físico intrínseco que carateriza o fator ilhéu; ela é, igualmente, excludente, já que parte da nossa identidade e autenticidade próprias para se excluir ou afastar-se das culturas de origem; parte, ainda, do princípio falacioso de que existe unicidade cultural na África ou na Europa, uma asserção desmentida pelos fatos e pela realidade. Aliás, para sermos mais sinceros e precisos, unicidade cultural é coisa que não existe, sequer em Cabo Verde, que é o caso que nos interessa no momento.

Há uma matriz comum, donde surgiu a identidade cabo-verdiana. Essa matriz, como já antes disséramos, nasceu nas ilhas de Santiago e Fogo, ilhas de povoamento antigo, tendo-se, posteriormente, dispersado pelas restantes ilhas do arquipélago, ganhando, em cada uma delas, novos contornos, sem perder ou adulterar profundamente e de forma irreconhecível essa mesma matriz de base. Antes pelo contrário, ela se enriqueceu com as novas contribuições.

E nem se pense que somos caso único, especial ou específico em matéria de miscigenação de raças e culturas, como amiúde afirmamos, para daí tirarmos ilações infundadas e sem crédito do ponto de vista científico.

Existem outros casos similares na África, como São Tomé e Príncipe, Maurícias, Sheychelles, Comores... A única diferença é que, naqueles Estados insulares, micro-Estados como nós, de composição mestiça, nunca se coloca em causa a sua identificação africana.

A frase, que vimos avaliando, sem ser, naturalmente, por culpa do seu autor, tem permitido, entre nós, todas as extrapolações possíveis e imaginárias, a maioria delas ilegítimas e sem substância: desde nos considerarmos como mais europeus do que africanos, à divisão de Cabo Verde entre Macaronésia e África, passando por conceitos de civilização de mais do que duvidosa aplicação e entendimento, em termos operatórios, como nos apelidarmos de "atlânticos", ou ainda autorizando a tese da chamada diluição da África quando, na mesma medida, não se fala na diluição da Europa entre nós, pois que o processo da nossa miscigenação a isso conduziu, uma vez que deu origem a uma terceira cultura, a cabo-verdiana, parida de outras que a geraram.

Para nossa melhor afirmação enquanto povo, melhor seria assumirmos a nossa História na sua integralidade, sem complexos de superioridade ou de inferioridade. 
Faríamos bem melhor se, em vez de contestarmos a nossa maternidade, já que foram as mulheres africanas, na sua esmagadora maioria, que deram à luz as crianças crioulas, nos reconciliássemos com a nossa História e tivéssemos orgulho naquilo que os nossos antepassados negros, brancos e mestiços foram capazes de construir ao longo dos séculos, contrariando a natureza ignara. Faríamos bem melhor se, ao contrário de tentarmos, permanentemente, reescrever o nosso passado, ao sabor dos tempos e da conjuntura, o conhecêssemos mais e melhor, sem processos de intenção de julgar ou corrigir a própria História, porque o nosso mister é conhecê-la e compreendê-la, quanto mais não seja para aprendermos com os erros do antanho e os não repetir no presente ou no futuro.

Uma coisa é certa: as ilhas, as nossas ilhas não podem ser arrastadas ou deslocadas, qual "jangada de pedra", mais para o Norte; o código genético cabo-verdiano encerra marcas africanas, que não podem ser pura e simplesmente apagadas, com o simples ato de passagem de uma borracha por cima; por mais que o nosso ego fique inflado, quando os europeus nos acham diferentes, dizendo-nos que nós não somos africanos, a verdade é que não nos identificam como europeus, o que não somos de fato, embora tenhamos, também no nosso $\mathrm{ADN}$, as suas marcas, as quais, do mesmo modo, não podem ser simplesmente riscadas, por qualquer passe de mágica; Cabo Verde só tem interesse para a Europa se continuar a fazer jus à sua vocação de ponte entre culturas e no quadro da integração africana.

O fato de, num Cabo Verde já independente, estarmos a debater este movimento literário e político, a Claridade, que trouxe à ordem do dia a realidade cabo-verdiana, vem demonstrar quão importantes as suas reflexões foram para nós e permanecem. Não aceitamos integralmente as posições de cada autor, quando a realidade se alterou e a percepção crítica pode ser mais ampla, mas sim, através delas, podemos ser capazes de ir além. De outro modo, cairíamos no imobilismo.

Baltasar Lopes não diminui em nada esta Nação, caso se considere que, além de sermos cabo-verdianos, e nós presentes tivemos o privilégio de poder sê-lo de parte inteira, sermos também parte do grande Continente ao lado: a África!

Dela nos afastamos, amiúde, para não sermos comparados com o negativo, o atrasado, o violento, o pouco desenvolvido, a escuridão da pobreza 
e a miséria, que demasiados recantos da África patenteiam. Dela queremos fugir, mas na maioria de nós, mesmo nos mais claros e caldeados, existem genes que, numa caravela ou noutro barco qualquer, aportaram às nossas ilhas. Vinham como capatazes de escravos, e também como escravas ou escravos, vinham a comércio. Vieram, e deles somos o resultado.

Compreender isso é o melhor legado que podemos deixar aos nossos netos, das ilhas geográficas e das muitas ilhas de cabo-verdianos plantadas pelo mundo fora.

\section{Quem somos nós?}

Em cada recanto do mundo, em casa de cachupa, de festa marcada, do mais simples ao mais erudito, a questão perfila-se.

Quem é este povo, unido no mar; como se vê ao espelho da grande Aventura Humana? Um solitário sem pertença? Um apartado de povos irmãos? Uma escala única sem contato com o exterior?

Pela tabela da História, longa e de memória de milhares e milhares de anos, a nossa caminhada é curta e vai cimentando-se na sabedoria do tempo.

Importa, no entanto, na atualidade, sabermos fazer perguntas, e se não formos capazes de encontrar respostas, que fiquemos com a coragem de querer dialogar com as questões do âmago da nossa comunhão enquanto povo, sem nos considerarmos os donos da verdade.

O que falamos, que língua é esta que nos une e tantos atropelos tem à sua real e cabal existência?

Quem são estas caras, que memórias guardam sem saber?

Que doloroso passado este que nos impede de aceitar as duas forças antagônicas que em nós habitam?

Enquanto não soubermos, ou não pudermos, ou não quisermos antever a verdade da resposta, façamos só as perguntas e adiemos o virar da página, quando todas as detrás estiverem interpretadas.

Haverá um outro Simpósio da Claridade, dentro de dez, vinte anos, e ele voltará a ter o seu lugar de destaque. Então, far-se-á outro balanço destas questões e mais campo desbravado na interioridade da presença cabo-verdiana e sua questão fulcral. Quem somos nós?

Não será tempo, então, de nos reconciliarmos conosco próprios e com a nossa História, sem continuarmos, permanentemente, ad eternum, a questionar a origem dos nossos históricos progenitores, escolhendo apenas os 
que se nos afiguram mais nobres ou mais importantes, sempre ao sabor do momento ou do interlocutor presente, que ora nos adula, ora nos rejeita, conforme for do seu próprio interesse? Reflitamos... e façamos de modo que o reencontro com a nossa História nos indique o caminho certo do futuro tão ansiado quanto desejado.

\section{Referências bibliográficas}

BRÁSIO, Padre António. Monumenta missionária africana, 2. Série, Vol. II, Doc. 117. . Monumenta missionária africana, 2. Série, Vol. IV, Doc. 149.

FERREIRA, Manuel. A aventura crioula ou Cabo Verde - uma sintese cultural e étnica. 2. ed. aumentada. Lisboa: Plátano, 1973.

FREYRE, Gilberto. Aventura e rotina. Rio de Janeiro: Topbooks, 1999. Prefácio de Alberto da Costa e Silva.

LOPES, Baltasar. Cabo Verde visto por Gilberto Freyre: apontamentos lidos ao microfone da rádio Barlavento. Praia: Imprensa Nacional, 1956.

MARIANO, Gabriel. Do funco ao sobrado ou o mundo que o mulato criou. In: Colóquios cabo-verdianos, 22, J.IU., Lisboa, 1959.

PEREIRA, Daniel A. Marcos cronológicos da Cidade Velha. 2. ed. (revista e aumentada). Praia: IBNL, 2009. . Das relações históricas Cabo Verde/Brasil. Brasília: Fundação Alexandre de Gusmão, 2011.

Autor convidado. 